\title{
WHY SOCIAL EMERGENCE? \\ DISCUSSING THE USE OF ANALYTICAL METAPHYSICS IN SOCIAL THEORY.
}

\author{
JEROEN VAN BOUWEL \\ Centre for Logic and Philosophy of Science \\ Ghent University, Belgium \\ E-mail: Jeroen.VanBouwel@UGent.be
}

\begin{abstract}
Recently the concept of emergence has been used in social theory to understand and defend social causation and nonreductive individualism (cf., Refs. 1, 2 and 3). In this paper, I want to analyse what the contribution of analytical metaphysics, and, in particular, the concept of emergence is, or might be, to the discussion in social theory. Especially Keith Sawyer's use of emergence in his defence of social explanation will be scrutinized. Therefore, it will be important to distinguish ontological from epistemological emergence. Where Sawyer focuses on ontological emergence, I will argue that social explanation might better be defended by putting emphasis on pragmatic aspects of explanation and considering emergence as an epistemological category.
\end{abstract}

\section{Introduction}

Recently, Keith Sawyer has put emergence high on the agenda in the philosophy of social science. Emergence would help to conceptualize the relation between individual and society and to defend social causation and social explanation (cf., Refs. 1, 2 and 3). In this paper, I want to analyse what the contribution of analytical metaphysics to the discussions in social theory is, or can be, by scrutinizing what the added value is of introducing emergence. Especially, the way Keith Sawyer is using emergence to conceptualize the individual-collective relation in social science, paying attention to the analogies with philosophy of mind, will be examined.

In the first section, I will briefly discuss the relation between philosophy of mind and social theory. Secondly, I will introduce Keith Sawyer's social translation of nonreductive materialism in section 2. The place of emergence in Sawyer's framework and the use of emergence in social theory will be discussed in section 3. Subsequently, questions will be raised about Keith Sawyer's use of emergence in his defence of social explanation in section 4. 
Therefore, it will be important to distinguish ontological from epistemological emergence. Where Sawyer focuses on ontological emergence, I will argue that social explanation might better be defended by putting emphasis on pragmatic aspects of explanation and considering emergence as an epistemological category. In section 5, conclusions will be drawn.

\section{Philosophy of mind and social theory}

Conceptualizing the relation between the individual and the collective has always been a central issue in social theory. In recent years, the concept of emergence has been used in order to illuminate the individual-collective relation in social theory, drawing attention to the analogies with philosophy of mind. The typical questions in philosophy of mind can easily be translated to social theory, e.g.: What is the relation between the lower-level physical entities, respectively individuals, and higher-level mental entities, resp. social entities? Can we assign causal efficaciousness to our mental states, resp. social entities or social properties? Are explanations invoking mental states, resp. social factors, good explanations? How can our mind, resp. the social, influence the physical world, resp. the individuals, granting that our intentional actions and our perceptions, resp. individual actions, seem to entail that mental events, resp. social events, can be, respectively, causes and effects of physical events, resp. individual actions? Etc.

As the idea of nonreductive physicalism/materialism has been having a lot of supporters the last decade - Sawyer calls it the consensus position in philosophy of mind nowadays (Ref. 4, p. 539) - an interesting exercise would be to transfer this nonreductive physicalism to social theory and the debates on methodological individualism and holism in the philosophy of social science. Let us briefly sketch the contours of that exercise.

Two characteristics of nonreductive physicalism are salient:

a) dependence: mental properties are properties of physical objects

b) distinctness: mental properties are distinct from physical properties

The first claims that higher level entities are composed of and are nothing more than their lower level components. This is sometimes expressed as the supervenience claim. ${ }^{a}$ In this sense, a position different from Cartesian dualism is defended. The second claim is a reaction against reductionism,

${ }^{\mathrm{a}}$ I adopt the most common version of supervenience in the consensus position here. Some will object that the original definition of supervenience does not express dependence, but only determination, cf., Ref. 5 . 
and type-identity theory (which denies distinctness as it asserts that mental properties are identical with physical properties). This is where emergentists usually enter; they reject a dualist ontology, but at the same time argue that higher-level phenomena do have causal power.

Starting from the analogies between the philosophy of mind debate and the debate in social theory, we can articulate nonreductive physicalism/materialism in social theory. First, the rejection of dualism: the so-called collectivist sociologists and social theorists have been proposing theories in which social properties are causal antecedents. Often these properties were considered to have ontological autonomy, but how can they have causal power if they are ontologically autonomous? Do we have two distinct ontological orders, a dualist ontology, when 'structural' sociologists are claiming that social terms and concepts are real? This opens up the road to the criticism of hypostatizing the social group as an entity. To avoid dualism the social version of nonreductive physicalism should put emphasis on (a) the ontological dependence of the higher social level on the lower individual level. Secondly, many social theorists do not want to reduce the social to the individual, and will have to find an argument for (b) the distinctness of social causation, analyzing the ontological relation between the higher-level phenomena and individual actions.

\section{Keith Sawyer's nonreductive individualism}

Keith Sawyer has recently developed such a social version of nonreductive physicalism more thoroughly; one that "would be to hold that only individuals exist and that social entities do not have a distinct existence, yet there may be irreducible social properties and social laws" (Ref. 1, p. 559). He combines ontological individualism (dependence) with a rejection of methodological individualism and reduction (distinctness). Let us analyse the metaphysical concepts he is using in the elaboration of his nonreductive individualism (NRI).

Sawyer considers himself to be an ontological individualist, even though he considers social properties, social structures and social mechanisms to be real. "NRI is compatible with the ontological assumption of individualism - social groups are composed of nothing other than individuals" (Ref. 4, p. 554). What is then the status of social entities and properties? "Ontological individualism accepts that collectives do not exist apart from their constituent individuals, and NRI accepts this ontological commitment of individualism" (Ref. 2, p. 219). This individualism does, however, not im- 
ply reduction: "there are strong grounds for believing that this reduction is not possible, even though there is nothing in the universe other than physical matter. The argument is based on supervenience, multiple realizability, and wild disjunction" (Ref. 1, p. 555).

(a) Supervenience. Sawyer starts from ontological individualism and token identity (Ref. 4, p. 541) and in his words:

"token event identity entails that emergent higher-level properties supervene on the system of lower-level components. Supervenience refers to a relation between two levels of analysis and states that if two events are identical with respect to their descriptions at the lower level, then they cannot differ at the higher level". (Ref. 1, p. $555-556)$

As supervenience does not suffice to substantiate irreducibility, Sawyer adds multiple realizability to his argument:

"If supervenience is to be used to ground a nonreductive stance, one must develop a version of the supervenience thesis that argues that the reductionist approach of methodological individualism is not possible for some social properties, despite ontological individualism. I will argue that to reject methodological individualism one must show how type identity versions of supervenience might not obtain. ... nonreduction due to multiple realizability is now the consensus position in the philosophy of mind". (Ref. 4, p. 544-545)

(b) Multiple realizability. "The argument is based on the notion of multiple realizability: the observation that although each mental state must be supervenient on some physical state, each token instance of that mental state might be implemented, grounded, or realized by a different physical state" (Ref. 1, p. 556).

(c) Wild disjunction. Multiple realizability alone does not necessarily imply irreducibility; if there are only a few realizing states, or if those states display some common features, the reduction may not be problematic. Therefore, Sawyer introduces the idea of wild disjunction:

"reduction would be difficult if the neurobiological equivalent of a psychological term were an otherwise unrelated combination of many neurobiological concepts and terms .... Fodor termed such a realization wildly disjunctive. If a higher-level property is realized by a wildly disjunctive set of lower-level properties, then the physi- 
cal equivalent of a psychological law must contain wildly disjunctive terms". (Ref. 1, p. 557)

This can be used to show "how a higher-level property could be supervenient on and yet not reducible to its lower-level base" (Ref. 1, p. 575).

Here the metaphysical battle can be declared open: what is the status of supervenience, is multiple realizability a good argument for the nonreducibility of the social level, and what about wild disjunction? Which arguments are decisive here? Let us hold our metaphysical horses — or should I say, unicorns - for now, and discuss the last metaphysical concept that is central in Saywer's account: emergence.

\section{The introduction of emergence and its use(fullness) in social theory}

Sawyer links his NRI and the existence of irreducible social properties to the idea of emergence:

"Emergentism does not claim that all higher-level properties are irreducible; some of them are predictable and derivable from the system of lower-level components. Only in cases where the relation between higher-level and lower-level properties is wildly disjunctive beyond some threshold of complexity will the higher-level property not be lawfully reducible". (Ref. 1, p. 558)

Emergence should be understood as follows, according to Sawyer:

"when basic physical processes achieve a certain level of complexity of an appropriate kind, genuinely novel characteristics emerge; the emergent higher-level properties could not, even in theory, be predicted from a full and complete knowledge of the lower-level parts and their relations. Further, they could not be reduced to properties of the parts and their relations, even though those properties are supervenient on and thus determined by the system of parts"

(Ref. 1, p. 554).

How can this idea of emergence presented by Sawyer help us in developing social theory? Let me browse through some examples of the use of emergence in social theory, as I am interested in how analytical metaphysics could contribute to social theory (and analyze whether it actually does). Sawyer has enumerated some social theorists that apply emergence 
in their work, and distinguishes collectivist emergentists from individualist emergentists (Ref. 1, p. 552). Let us start with that distinction.

The individualist emergentists in social theory believe that macro-social properties and laws can be explained in terms of properties and laws about individuals and their relations. The existence of emergent system properties that are not possessed by the parts does not entail irreducibility of those properties, according to them (which might be unexpected as emergence is traditionally interpreted as the contrary to reduction, cf., infra, footnote b). Examples of this individualist emergence can, for instance, be found in the work of James Coleman who adopts emergence in his Foundations of Social Theory, ${ }^{6}$ and in Thomas Schelling's classic Dynamic Models of Segregation in which he uses a checkerboard simulation to explain the emergence of residential segregation. ${ }^{7}$

George Homans, elaborating behavioural sociology, defends in his book Social Behavior how emergent properties could be explained using psychological propositions: " is how the emergence is to be explained. I say that the emergence, and the nature of the properties that emerge, are to be explained by psychological propositions" (Ref. 9, p. 229). Homans does not deny that something new can emerge out of the interactions between individuals. The explanation of these emergent properties can, however, be provided on the individual and psychological level:

"The great example of a social fact is a social norm, and the norms of the groups to which they belong certainly constrain towards conformity the behavior of many individuals. The question is not that of the existence of constraint, but of its explanation .... The norm does not constrain automatically: individuals conform, when they do so, because they perceive it is to their net advantage to conform, and it is psychology that deals with the effect on behavior of perceived advantage" (Ref. 10, p. 60).

Robert Axelrod, in Ref. 11, developed artificial society simulations which enable him to explore the emergence of new political actors: how do higher-level actors (i.e., supranational entities) emerge out of the interaction of lower-level actors (i.e., nation-states)? Understanding these mechanisms of emergence, aggregation and disaggregation helps us in the development of global policies, according to Axelrod, e.g., concerning the question of sustainability: 
"The emergence of new political actors is fundamental to the question of sustainability. One of the main problems of attaining sustainability is the tragedy of the commons. The tragedy of the commons arises when many independent actors (people, villages, states, or whatever) each 'overgraze' because there is no mechanism to enforce the collective interests of all against the private interests of each. This leads to resource depletion, elimination of bio-diversity, overpopulation, war, and other major social problems. A major route to the prevention of the tragedy of the commons is the emergence of a political actor based upon the organization of previously independent actors." (Ref. 11, p. 20)

Axelrod's simulation might be a bit simple in set-up, but it does reproduce historically observed patterns, e.g., imperial overstretch. Axelrod's analysis of emergence aims at answering questions like: what are the minimal conditions necessary for a new actor to emerge? How is emergence affected or constituted by the basic actors? How can new actors emerge out of the existing ones? The simulation model of Axelrod that he presents to answers these questions, presupposes that the instances of emergence it describes do not preclude the formulation of reductive, individualistic explanations.

If we evaluate the conceptualization of emergence in the work of Coleman, Schelling, Homans and Axelrod within the framework of Sawyer's NRI (cf. section 2), we conclude it is consistent with token identity and supervenience, but not with multiple realizability and wild disjunction; the existence of emergent properties that are not possessed by the parts does not entail irreducibility of those properties.

A second group of social theorists can be labelled collectivist emergentists. They believe that emergence is incompatible with reductionist individualism and explicitly draw on emergence to ground nonreductionist, nonindividualist social theories, e.g., Margaret Archer, ${ }^{12}$ Roy Bhaskar, ${ }^{13}$ and Peter Blau. ${ }^{14,15}$

Margaret Archer has elaborated the idea of morphogenetic dualism in her Realist Social Theory: The Morphogenetic Approach and works within the tradition of Critical Realism. The morphogenetic cycle consists of three phases: "prior structural conditioning $\rightarrow$ social interaction $\rightarrow$ structural elaboration" (Ref. 12, p. 328). Through this cycle new properties emerge. The result of this emergence is described by Archer as follows:

"Once emergence has taken place the powers and properties defin- 
ing and distinguishing strata have relative autonomy from one another; Such autonomous properties exert independent causal influences in their own right and it is the identification of these causal powers at work which validates their existence, for they may indeed be non-observables" (Ref. 12, p. 14).

Hence, according to Archer, emergence leads to independent causal powers on the higher level, i.e., higher-level properties exert an autonomous causal influence.

Archer endorses Roy Bhaskar's realist conception of causal powers, but Bhaskar's Transcendental Realism does not only talk of emergent properties, but also of emergent entities, 'things' (Ref. 16, p. 51), to which causal autonomy is ascribed.

Finally, Peter Blau, does talk of emergent properties too in his work. Especially in his later work, ${ }^{14,15}$ he is emphasizing the inherent antireductionistic character of emergent properties (Ref. 15, p. 10). The social structure is not merely a conceptual representation of a sociologist, but it does exert causal influence on individuals (Ref. 15, p. 15-16 and Ref. 14). Several have criticized Blau for reifying social structure. Others reproach him that his ideas on emergence are not satisfactorily elaborated.

Considering the work of Archer, Bhaskar and Blau, one can conclude that these collectivist emergentists - interpreting emergent properties as ontologically autonomous, exerting independent causal influences in their own right - go against the supervenience claim, present in Sawyer's NRI.

In general, reflecting on the use of emergence by these social theorists both the individualist and collectivist emergentists - we can notice some conceptual overstretch. Sawyer draws the same conclusion and criticizes the way emergence is used by social theorists; he articulates how they deviate from his philosophical view of emergence, and he evaluates the use of emergence in social theory by applying his framework of NRI and emergence as the standard, defining the 'correct' interpretation of emergence. Individualist emergentists do not take MR and wild disjunction into account, according to Sawyer (Ref. 1, p. 564); they presume type-identity. The collective emergentists have a too autonomous view of emergent properties or reify social structure, such that society becomes ontologically autonomous from individuals.

Sawyer's strategy is one way of dealing with the conceptual overstretch of emergence in social theory, i.e., we need analytical metaphysics to assure some conceptual hygiene and decide on what emergence precisely is. This 
could mean, for instance, following Sawyer's interpretation of emergence as the new standard. A second strategy would be that we should be aware of the poly-interpretable nature of emergence, and look for an alternative way to deal with emergence, for instance, by introducing the distinction between ontological and epistemological emergence. I will defend this second strategy, as the first strategy faces some problems which will be enumerated in the following section.

\section{How to evaluate Sawyer's metaphysics? Questioning social emergence}

Evaluating Sawyer's social emergence, I first want to pay attention to the distinction between ontological and methodological issues in social theory. Discussing the debate between individualists and collectivists, Sawyer himself distinguishes two levels, namely: "an ontological level, concerning arguments about what entities and properties exist in the world, and a methodological or epistemological level, concerning the proper way to proceed in scientific practice" (Ref. 4, p. 537). Furthermore, he rightly points out that: "The logical error of making ontological arguments in support of methodological claims is quite common in the philosophy of social science" (Ref. 4, p. 538). I fully agree with these two remarks of Sawyer, i.e., ontological and methodological issues are often mixed up and we should try to clearly distinguish them. This does, of course, not imply that ontological issues are completely irrelevant for methodological issues or vice versa.

Notwithstanding his own remarks, I do notice that Sawyer is mainly interested in getting the ontological arguments sound, “... to make an argument for social causation that is consistent with ontological individualism" (Ref. 4, p. 540), and he seems to presuppose that the ontological framework has to be fully elaborated or fixed, so we can stipulate methodological recommendations. Does Sawyer adopt a similar strategy as the one he just claimed to be erroneous, i.e., developing ontological arguments out of which methodological consequences seem to follow automatically? Why does he not make a clear distinction between ontological and epistemological versions of emergence - a distinction that has been made by scholars before, e.g., Ref. 17 ?

Ontological emergence claims that novel, real and irreducible properties do exist (or come into existence) on the higher level. These emergent properties are just as real as physical properties. Sawyer seems to adhere to the ontological version of emergence as the following quote shows: 
"For the latter properties — real emergent social properties - explanation may of necessity involve irreducible social properties and laws. I will draw on analyses of complexity, self-organization, and emergence to explore these questions. I conclude that for certain social mechanisms, we may be required to pursue macrosociological explanation in terms of emergent social properties, not only because of epistemological limits to current science but because of the structure of reality" (Ref. 18, p. 270).

The structure of reality (with its real emergent social properties) is the source of emergence, not merely our epistemological capacities, according to Sawyer.

Following epistemological emergence, on the other hand, the concept of emergence is characterized in terms of possibilities of and limits on human knowledge of complex systems: it deals with the (in)adequacy of reducing theories and is based on the fact that it sometimes appears to be impossible to understand the global behavior of a complex system by analyzing the local behavior of the individual parts. Hence, epistemological emergence regards the ineliminability of some higher-level descriptions or explanations, and defends that in science some phenomena or questions can best be understood or answered by referring to properties on the higher level. This version of emergence has been argued for by, e.g., Andy Clark ${ }^{19}$ and Robert Batterman. ${ }^{20}$

It should be emphasised that subscribing to epistemological emergence does not imply any precipitant ontological statements, i.e., that there would exist a distinct class of real emergent properties. One can accept epistemological emergence without ontological emergence. Sawyer does not consider this possibility, and defends ontological emergence, a position which is (at least) problematic. Firstly, the 'novel' causal powers of emergent properties raise questions about downward causation and the causal completeness of the lower level. Secondly, Sawyer's ontological emergence is embedded in his NRI argued for by referring to multiple realizability (MR) and wild disjunction (WD). MR and WD suffice to prove irreducibility and substantiate emergence, according to Sawyer, but for both MR (cf. Ref. 21) and WD (cf. Ref. 22) arguments have been formulated to question their incompatibility with reduction. Thirdly, by subscribing to ontological emergence in order to secure the necessity and indispensability of social, higher level explanations and social, higher level laws, Sawyer follows an old strategy in philosophy of the social sciences. This strategy overlooks pragmatics as 
it wants an a priori or a-contextual certainty, and presupposes an identity between causation and explanation, a move we have criticised before (cf. Refs. 23, 24).

Sawyer will have to defend his ontological emergence against these three weaknesses. I want to propose to subscribe to the epistemological version of emergence. This version can support the program of social theory - invoking social factors in the explanation of phenomena - including a version of nonreductive individualism. Discussing the different levels of explanations, we have shown in earlier work that in some cases explanations on the social level are preferable because of the efficient way in which they provide us with the explanatory information required, even though an explanation on the individual level is possible in principle (cf., Ref. 25). A social-level explanation might be more efficient, and/or provide us with better explanatory information, and/or be easier to construct, and/or supply better understanding, because of the complexity or redundancy of the individuallevel explanation. Whether an individual-level or a social-level explanation is the best, depends on the explanatory request. Hence, instead of a priori discussing the possibility of reduction, the attention should rather go to the pragmatic surplus the higher-level explanations might have in the explanatory practice of the social sciences.

\section{Conclusion: If at all...}

In discussing the contributions of some social theorists in section 3, we have noticed a manifest conceptual overstretch in the use of emergence. It is Sawyer's merit to try to remedy this situation and to be more explicit about how to understand or conceptualize emergence. Therefore, he turns to philosophy of mind and analytical metaphysics which can provide some conceptual clarity. The development of a nonreductive individualism analogous to the nonreductive physicalism of the philosophy of mind literature is a constructive and valuable proposal to understand emergence in social theory, and causality in general. The concepts introduced, i.e., supervenience, multiple realizability and wild disjunction could help social theorists to sharpen their ideas on emergence.

Denying the distinction between ontological and epistemological emergence, however, Sawyer does seem to want to convince us that subscribing to ontological emergence is indispensable in legitimizing social explanations (and - preferably - his particular version of emergence ${ }^{\mathrm{b}}$ ), which is incor-

\footnotetext{
${ }^{\mathrm{b}}$ Sawyers interpretation of emergence is rather traditional and mainly used as the con-
} 
rect.

Moreover the ontological version raises several problems (cf., supra) and risks turning into an unending battle of metaphysical intuitions, rather than contributing to the analysis of scientific practice. The metaphysical debates do help us to clarify concepts, but often open up the road to the imposition of the 'correct' ontology for all situations, as is done, for instance, by the ontological emergentist Sawyer postulating the existence of emergent properties in order to 'prove' the causal efficaciousness of the social level (putting the question what emergence would 'prove' and how to 'prove' emergence between brackets). Why can we not just start from the existing competing social explanations, and compare which of the ontological partitions of social reality - present in the different explanations - serves us the best explanatory information? In stead of getting paralysed by ontological or metaphysical debates in social theory, I want to suggest that more attention should be paid to methodology and explanatory practice, and the information we want, in order to maximize (our understanding of) good scientific practice (as done in Refs. 25, 27).

Although we cannot deny the impact of metaphysical concepts and ontological issues in general - and, therefore, attention should be paid to those issues - I claim that our views on methodological and explanatory options in the social sciences have too long been dictated by our views on ontology and causation. Introducing epistemological emergence can help us in giving less weight to metaphysical and ontological debates, and more to methodological ones.

Returning to the philosophy of mind, where we started our journey, we can find some scholars that warn us (just like I did) not to get paralysed by these ontological or metaphysical debates, but rather pay more attention to methodology and explanatory practice. E.g., Tyler Burge states the following about the worries that exist in philosophy of mind on mental causation:

"But what interests me more is the very existence of the worries. I think that they are symptomatic of a mistaken set of philosophical priorities. Materialist metaphysics has been given more weight than it deserves. Reflection on explanatory practice has been given too little" (Ref. 28, p. 97).

trary to reduction, while recent contributions propose to review this opposition and explore a more nuanced conceptualisation of emergence which is independent from reduction (cf., Ref. 26). 
A similar idea has been defended by Lynne Rudder Baker:

"Given standard metaphysical and methodological assumptions, not only has the problem of mental causation proved to be intractable but even worse: the same reasoning that leads to scepticism about mental causation also leads to scepticism about almost all supposed 'upper-level' causation, and hence to skepticism about explanations that mention 'upper-level' properties, including explanations offered by the special sciences and much of physics. Of course, pointing out such skeptical conclusions, even of this magnitude, is not a refutation of the metaphysical assumptions that generate them. But skeptical consequences may well be a motivation for taking a different philosophical tack. ... My proposal is to perform a methodological about-face. Instead of beginning with a full-blown metaphysical picture, we should begin with a range of good explanations, scientific and commonsensical. ... Although my proposal has a strong pragmatic cast, it is by no means an anti-realist suggestion. I am not equating what is real with what is needed for explanations and predictions. The point is, rather, that we have no better access to reality than what is required for cognitive success, construed broadly enough to include what is cognitively required for achieving goals in both science and everyday life." (Ref. 29, p. 94-95)

Using the analogy between the discussion physical-mental and individual-collectivism/holism, we risk running into metaphysical debates and getting stuck (just like the philosophers of mind), presupposing these debates have to be resolved first or hoping that analytical metaphysics will provide us with some sound a priori worldview. Too much attention to ontological and metaphysical issues (as is done in the contributions of Sawyer), might lead to the neglect or obstruction of fruitful methodological issues in social theory. If at all we want analytical metaphysics to get involved, be aware of the hazards.

\section{Acknowledgments}

The author is Postdoctoral Fellow of the Research Foundation-Flanders (FWO).

\section{References}

1. R. K. Sawyer, Emergence in Sociology: Contemporary Philosophy of Mind and Some Implications for Sociological Theory. American Journal of Sociology 107 (3), 551-585 (2001).

2. R. K. Sawyer, Nonreductive Individualism: Part II - Social Causation. Philosophy of the Social Sciences 33 (2), 203-224 (2003). 
3. R. K. Sawyer, Social Emergence: Societies as Complex Systems. Cambridge: Cambridge University Press (2005).

4. R. K. Sawyer, Nonreductive Individualism: Part I - Supervenience and Wild Disjunction. Philosophy of the Social Sciences 32 (4), 537-559 (2002).

5. T. Grimes, Supervenience, Determination and Dependence. Philosophical Studies 62, 81-92 (1991).

6. J. Coleman, Foundations of Social Theory. Cambridge, MA: Harvard University Press (1990).

7. T. Schelling, Dynamic Model of Segregation. Journal of Mathematical Sociology 1, 143-186 (1971).

8. G. Homans, Social Behavior: Its Elementary Forms. New York: Harcourt, Brace \& World (1961).

9. G. Homans, Commentary. Sociological Inquiry 34, 221-231 (1964).

10. G. Homans, The Nature of Social Science. New York: Harcourt, Brace \& World (1967).

11. R. Axelrod, A Model of the Emergence of New Political Actors. In: N. Gilbert and R. Conte (Eds.), Artificial Societies: The Computer Simulation of Social Life. London: University College London Press, 19-39 (1995).

12. M. Archer, Realist Social Theory: The Morphogenetic Approach. Cambridge: Cambridge University Press (1995).

13. R. Bhaskar, The Possibility of Naturalism. Brighton: Harvester Press (1979).

14. P. Blau, A Macrosociological Theory of Social Structure. American Journal of Sociology 83, 26-54 (1977).

15. P. Blau, Introduction: Diverse Views of Social Structure and Their Common Denominator. In: P. M. Blau and R. K. Merton (Eds.), Continuity in Structural Inquiry. Beverly Hills, California: Sage, 1-23 (1981).

16. R. Bhaskar, A Realist Theory of Science. New York: Verso Classics (1975).

17. M. Silberstein and J. McGeever, The Search for Ontological Emergence. The Philosophical Quarterly 195, 182-200 (1999).

18. R. K. Sawyer, The Mechanisms of Emergence. Philosophy of the Social Sciences 34 (2), 260-282 (2004).

19. A. Clark, Being There: Putting Brain, Body, and World Together Again. Cambridge, MA: The MIT Press (1996).

20. R. Batterman, The Devil in the Details. Oxford: Oxford University Press (1999).

21. J. Zahle, The Individualism-Holism Debate on Intertheoretic Reduction and the Argument from Multiple Realization. Philosophy of the Social Sciences 33 (1), 77-99 (2003).

22. E. Sober, The Multiple Realizability Argument Against Reductionism. Philosophy of Science 66, 542-564 (1999).

23. J. Van Bouwel and E. Weber, The Living Apart Together Relationship of Causation and Explanation. Philosophy of the Social Sciences 32 (4), 560569 (2002).

24. J. Van Bouwel, Individualism and Holism, Reduction and Pluralism. Philosophy of the Social Sciences 34 (4), 527-535 (2004).

25. E. Weber and J. Van Bouwel, Can we dispense with the structural explana- 
tion of social facts? Economics and Philosophy 18, 259-275 (2002).

26. M. Kistler, New perspectives on reduction and emergence in physics, biology and psychology. Synthese 151 (3), 311-312 (2006).

27. J. Van Bouwel and E. Weber, Remote Causes, Bad Explanations? Journal for the Theory of Social Behaviour 32 (4), 437-449 (2002).

28. T. Burge, Mind-Body Causation and Explanatory Practice. In: J. Heil and A. Mele (Eds.), Mental Causation. Oxford: Clarendon Press, 97-120 (1993).

29. L. Rudder Baker, Metaphysics and Mental Causation. In: Heil, John and Alfred Mele (Eds.), Mental Causation. Oxford: Clarendon Press, 75-95 (1993). **notused ${ }^{* *}$

30. J. Kim, Supervenience, Emergence, Realization, Reduction. In: M.J. Loux and D.W. Zimmerman (Eds.), The Oxford Handbook of Metaphysics. Oxford: Oxford University Press, 556-584 (2003).

31. L. Udehn, Methodological Individualism: Background, History and Meaning. London: Routledge (2001). 